\title{
Exploring factors that might influence primary- care provider discussion of and recommendation for prostate and colon cancer screening
}

This article was published in the following Dove Press journal: International Journal of General Medicine

\author{
Christine E Kistler' \\ Maihan $\mathrm{Vu}^{2}$ \\ Anne Sutkowi-Hemstreet ${ }^{3}$ \\ Ziya Gizlice ${ }^{4}$ \\ Russell P Harris ${ }^{5}$ \\ Noel T Brewer ${ }^{6}$ \\ Carmen L Lewis ${ }^{7}$ \\ Rowena J Dolor ${ }^{8}$ \\ Colleen Barclay ${ }^{5}$ \\ Stacey L Sheridan' \\ 'Department of Family Medicine, \\ School of Medicine, ${ }^{2}$ Center for \\ Health Promotion and Disease \\ Prevention, University of North \\ Carolina at Chapel Hill, Chapel \\ Hill, NC, ${ }^{3}$ Napa County Office of \\ Education, Napa, CA, ${ }^{4}$ Biostatistical \\ Support Unit, Center for Health \\ Promotion and Disease Prevention, \\ ${ }^{5}$ Cecil G Sheps Center for Health \\ Services Research, ${ }^{6}$ Department of \\ Health Behavior, Gillings School of \\ Global Public Health, University of \\ North Carolina at Chapel Hill, Chapel \\ Hill, NC, ${ }^{7}$ Division of General Internal \\ Medicine, Department of Medicine, \\ University of Colorado School of \\ Medicine, Aurora, CO, ${ }^{8}$ Division of \\ General Internal Medicine, Duke \\ University School of Medicine, \\ Durham, NC, ${ }^{9}$ Reaching for High Value \\ Care Team, Chapel Hill, NC, USA
}

Correspondence: Christine E Kistler Department of Family Medicine, University of North Carolina at Chapel Hill, 590 Manning Drive, Chapel Hill, NC 27599, USA

$\mathrm{Tel}+19199660543$

Fax + I 9199666126

Email Christine_Kistler@med.unc.edu
Background: Primary-care providers may contribute to the use of low-value cancer screening. Objective: We sought to examine circumstances under which primary-care providers would discuss and recommend two types of cancer screening services across a spectrum of net benefit and other factors known to influence screening.

Patients and methods: This was a cross sectional survey of 126 primary-care providers in 24 primary-care clinics in the US. Participants completed surveys with two hypothetical screening scenarios for prostate or colorectal cancer (CRC). Patients in the scenarios varied by age and screening-request status. For each scenario, providers indicated whether they would discuss and recommend screening. Providers also reported on their screening attitudes and the influence of other factors known to affect screening (short patient visits, worry about lawsuits, clinical reminders/performance measures, and screening guidelines). We examined associations between providers' attitudes and their screening recommendations for hypothetical 90 -year-olds (the lowest-value screening).

Results: Providers reported they would discuss cancer screening more often than they would recommend it $(P<0.001)$. More providers would discuss and recommend screening for CRC than prostate cancer $(P<0.001)$, for younger than older patients $(P<0.001)$, and when the patient requested it than when not $(P<0.001)$. For a 90 -year-old patient, every point increase in cancerspecific screening attitude increased the likelihood of a screening recommendation $(30 \%$ for prostate cancer and $30 \%$ for CRC).

Discussion: While most providers' reported practice patterns aligned with net benefit, some providers would discuss and recommend low-value cancer screening, particularly when faced with a patient request.

Conclusion: More work appears to be needed to help providers to discuss and recommend screening that aligns with value.

Keywords: cancer screening, older adults, decision making, low-value care, colon cancer, prostate cancer

\section{Background}

Both to improve overall care and minimize costs, the medical community is increasingly focused on optimizing the net benefit of care by promoting the delivery of high-value care and decreasing delivery of low-value care. ${ }^{1,2}$ Net benefit has been defined by the US Preventive Services Task Force (USPSTF) as the balance of benefits and harms of medical care. ${ }^{1,3}$ When evidence demonstrates that the magnitude of harms outweighs the magnitude of benefits from preventive services, these services are considered to confer net harm. Though value is a more expansive term than net benefit (including issues 
such as efficiency, timeliness, equity, and sustainability), in general, preventive services that confer net harm are generally considered to be of low value. ${ }^{4,5}$ While preventive services, such as cancer screening, are important tools for promoting health, they can be overused and their net benefit can change over a patient's lifetime. For example, while the public has embraced cancer screening, ${ }^{6}$ medical evidence demonstrates clearly that some cancer-screening tests cause more harm than benefit, resulting in net harm to the public and low-value care. ${ }^{7,8}$ Two preventive services, prostate cancer screening at all ages and colorectal cancer (CRC) screening in older adults, are considered low value care and exemplify some key issues with low value screening. Completion of these tests is strongly influenced by providers' recommendations and patients' age and request for the service, which we review herein.

Two cancer-screening services often considered of low value by various organizations and guidelines at older ages are prostate cancer screening and $\mathrm{CRC}$ screening. CRC screening is of high value for younger adults in their $50 \mathrm{~s}$ and $60 \mathrm{~s}$, but provides less benefit at older ages, particularly over age 85 years. ${ }^{9}$ Although the evidence is clear about net harm at older ages, US and international guidelines differ in approaches to recommendations on when to stop CRC screening. International screening programs typically provide guidance on when to start and how often to screen, but often do not address issues of low-value screening at the upper limits of age..$^{10,11}$ The USPSTF gives CRC screening a grade A recommendation (high certainty that the net benefit is substantial) for adults aged 50-75 years, a grade C (at least moderate certainty that the net benefit is small) for adults aged 76-85 years, and a grade D (moderate or high certainty that the service has no net benefit or that the harms outweigh the benefits) for those $>85$ years of age. ${ }^{12}$

The evidence for prostate cancer screening demonstrates net harm in average-risk populations. ${ }^{13}$ International guidelines for prostate cancer screening also vary widely between nations and even between different medical organizations within a given nation. ${ }^{14}$ USPSTF recommendations for prostate cancer screening in average-risk men continue to evolve, from a grade D recommendation for all ages from 2012 until 2017 (during which time this work was conducted $)^{15}$ to a grade $\mathrm{C}$ recommendation for adult men 55-69 years of age, and a grade D recommendation for those $\geq 70$ years of age. ${ }^{13}$ In spite of the marginal value of prostate cancer screening, a recent study found a third of older men with limited likelihood of benefit continued to receive screening. ${ }^{16}$ Indeed, much of the US public receives these services after they lose their expected benefit. ${ }^{17-20}$

Regardless of guideline concordance, provider recommendations increase screening significantly. ${ }^{20}$ Understanding how discussions and recommendations change depending on the type of screening may provide insights on how to improve cancer-screening value. Provider recommendations are both important and a potent source of guideline-discordant, lowvalue cancer screening. ${ }^{21-23}$ To provide guidance to providers to discuss and recommend screening, the shared decisionmaking workgroup of the USPSTF has encouraged providers to discuss and recommend services with clear net benefit, ${ }^{3}$ discuss and share decisions for services with marginal or uncertain benefit, ${ }^{24}$ and not initiate discussion about services that have either no benefit or net harm unless patients request discussion, recommendations have changed, or special circumstances alter the balance of benefits and harms. ${ }^{3}$ However, we do not understand how providers' discussions and recommendations change depending on the type of lowvalue cancer screening.

A robust body of work also notes the contribution of a patient's age to discussions and recommendations for cancer screening. Older patients have less chance to benefit from cancer screening than younger adults, due to shorter life spans, and yet receive all of the harms, either immediately or in the short period following screening (and the subsequent workup). Given the substantial time lag to benefit seen in both prostate cancer and CRC screening, older patients are likely to die before a cancer would have ever caused them harm. ${ }^{25-28}$ Ideally, providers would individualize recommendations and recommend preventive services for patients with the greatest likelihood of net benefit and discourage screening for those patients with likely net harm from screening. ${ }^{29,30}$ Despite recommendations for individualized CRC screening, research suggests that inappropriate prostate cancer and CRC screening are problematic, resulting in underuse in adults in good health and overuse in adults in poor health. ${ }^{17,19,20}$

Patient requests impact providers' discussions and recommendations, too. Even in the face of low-value care, patient requests impact providers' reports that they would recommend cancer screening. ${ }^{31-33}$ In both primary care and oncology visits, patient requests increase provider testing and treatment. ${ }^{32,34}$ While patient requests may be advantageous in high-value screening, they may be disadvantageous for low-value screening. In the face of patient requests, providers appear inadequately to take the value of the service (ie, the likelihood of benefit and harms) or their patients' age into account in their screening recommendations. ${ }^{35}$ The influence of patient requests appears to occur for both prostate cancer and $\mathrm{CRC}$ screening, ${ }^{21,31}$ and is insufficiently understood.

In addition to these more widely studied factors, other factors may play a role in providers' discussions and recom- 
mendations. One source of providers' low-value care may stem from their attitudes. ${ }^{36}$ Physicians with more risk-averse attitudes demonstrate higher levels of low-value recommendations and behaviors. ${ }^{36}$ Furthermore, primary-care providers have identified three factors as the primary drivers of aggressive, low-value care: inadequate visit time, clinical performance measures, and worries about lawsuits. ${ }^{31,37}$ To the best of our knowledge, the association between these factors and low-value screening has not been well explored.

While research has found that primary-care providers report discussion of and recommendations for low-value cancer-screening services for their patients due to a multitude of factors, we found no experimental study of the influence of these factors in providers' discussions and recommendations or how these factors interact with one another. Understanding how providers' discussions of and recommendations for screening services change in the face of varying cancer services, age, and patient requests may help to identify opportunities to improve clinical practice. To investigate when providers report that they would discuss and recommend cancer screening in older adults and how various factors are associated with these discussions and recommendations, we focused on two screening services (prostate cancer and CRC screening) that span the spectrum of value, including lowvalue screening. Our objective in this study was to examine when providers would discuss and recommend low-value screening, as described by the USPSTF recommendations on prostate cancer and CRC screening that were in effect at the time of this study. Improving our understanding of the circumstances in which providers discuss or recommend low-value cancer screening may help us to understand the factors affecting the use of low-value care more generally and point us toward interventions to minimize low-value care.

\section{Patients and methods}

This cross sectional survey was one of three primary studies conducted by the University of North Carolina Research Center of Excellence on Clinical Preventive Services. The other studies included a clinical trial examining methods for presenting information on the benefits and harms of screening to patients ${ }^{38}$ and a clinical trial of a patient CRC-screening decision aid in older adults to improve the appropriateness of CRC screening. The University of North Carolina and Duke University institutional review boards approved the study.

\section{Procedures and participants}

Clinics were part of the practice-based Duke Primary Care Research Consortium (PCRC), which includes community- based, nonteaching clinics in central North Carolina. From September to November 2012, we sent surveys to all 158 primary-care providers from 24 family-medicine or general internal medicine clinics affiliated with the Duke PCRC. We invited all family-medicine and internal medicine clinics in the Duke PCRC and their providers to participate. Eligible providers included primary-care medical doctors, doctors of osteopathic medicine, nurse practitioners, and physician's assistants, and excluded physicians in training, nurses, and other staff.

Study staff attended one of the monthly meetings of the Duke PCRC practice representatives to explain the study and invite participation. The project manager then sent eligible participants an introductory email providing additional information about the study and their potential participation in it. A representative of each medical practice, typically the clinic manager, distributed the paper-based survey to providers. Each survey included a US\$20 bill as an incentive. We based ongoing recruitment efforts and survey distribution on Dillman's total design method, with reminders for nonresponders at weeks 1,3 , and $7 .{ }^{39}$

\section{Survey design}

The surveys included hypothetical scenarios about prostate cancer and CRC screening accompanied by questions about whether providers intended discussions and recommendations about screening. They also included questions about providers' attitudes and other factors that might affect their screening. To counterbalance the order of the prostate cancer- and CRC-screening scenarios, we created two surveys (one with prostate cancer first and one with CRC first) and randomly assigned participants to receive one of these.

\section{Hypothetical scenarios and measurement of discussions and recommendations}

The hypothetical scenarios described patients who were male and healthy enough to undergo either CRC screening via colonoscopy or prostate cancer screening via prostatespecific antigen (PSA) (Figure 1). At the end of each scenario were two questions about whether the provider would discuss screening with that patient and whether the provider would recommend screening for that patient. For each of these, providers responded (yes/no) for a patient whose ages were 50,70 , and 90 years. The two sections on discussions and recommendations were broken down into whether the patient had or had not requested screening. This resulted in 12 yes/ no questions per scenario ( 24 total for the survey). While observed provider behavior compared to our scenarios might corroborate our results and offer added realism, other studies 
Prostate cancer screening scenario

Patient \#1: Mr. Morton is a white male with good cognitive status and no fatal disease. He has no family history of prostate cancer and no previous prostate findings or abnormal PSA tests. He had a normal PSA 2 years ago. His age is below.

\begin{tabular}{c|c|c|c|}
\cline { 2 - 4 } & \multicolumn{3}{|c|}{ If Mr. Morton's age is... } \\
\cline { 2 - 4 } $\begin{array}{l}\text { Do you discuss screening for prostate cancer } \\
\text { using PSA for this patient? }\end{array}$ & 90 years & 70 years & 50 years \\
\hline a. If patient does not request screening & & & \\
\hline b. If patient does request screening & Yes & Yes & Yes \\
& No & No & No \\
\hline & No & Yes & Yes \\
& & No & No \\
\hline
\end{tabular}

\begin{tabular}{c|c|c|c|}
\cline { 2 - 4 } & \multicolumn{3}{c}{ If Mr. Morton's age is... } \\
\cline { 2 - 4 } \multirow{2}{*}{$\begin{array}{l}\text { Do you recommend screening for prostate } \\
\text { cancer using PSA for this patient? }\end{array}$} & 90 years & 70 years & 50 years \\
\cline { 2 - 4 } & & & \\
\hline a. If patient does not request screening & Yes & Yes & Yes \\
& No & No & No \\
\hline b. If patient does request screening & Yes & Yes & Yes \\
& No & No & No \\
\hline
\end{tabular}

\section{Colorectal cancer screening scenario}

Patient \#2: Mr. Lewis is a white male with good cognitive status and no fatal disease. He has no family history of colon cancer and no risk factors or history of polyps. He had a normal colonoscopy 10 years ago. His age is below.

\begin{tabular}{c|c|c|c|}
\cline { 2 - 4 } \multicolumn{1}{c|}{} & \multicolumn{3}{c|}{ If Mr. Lewis' age is... } \\
\cline { 2 - 4 } $\begin{array}{c}\text { Do you discuss screening for colon cancer } \\
\text { using colonoscopy for this patient? }\end{array}$ & 90 years & 70 years & 50 years \\
\cline { 2 - 4 } & & & \\
\hline a. If patient does not request screening & Yes & Yes & Yes \\
& No & No & No \\
\hline b. If patient does request screening & Yes & Yes & Yes \\
& No & No & No \\
\hline
\end{tabular}

\begin{tabular}{c|c|c|c|}
\cline { 2 - 4 } \multicolumn{1}{c}{} & \multicolumn{3}{c|}{ If Mr. Lewis' age is... } \\
\cline { 2 - 4 } $\begin{array}{c}\text { Do you recommend screening for colon } \\
\text { cancer using colonoscopy for this patient? }\end{array}$ & 90 years & 70 years & 50 years \\
\cline { 2 - 4 } & & & \\
\hline a. If patient does not request screening & Yes & Yes & Yes \\
& No & No & No \\
\hline b. If patient does request screening & Yes & Yes & Yes \\
& No & No & No \\
\hline
\end{tabular}

Figure I Cancer-screening scenarios.

Abbreviation: PSA, prostate-specific antigen.

have shown that clinical vignettes correspond to providers' behavior in clinical settings. ${ }^{40,41}$

\section{Other measures}

To develop the survey, we took our chosen measures and organized them based on the principles for constructing surveys for primary-care providers..$^{42,43}$ Other measures included measures of provider screening attitudes and additional factors suggested by the literature as relevant to providers' discussions of and recommendations for cancer screening. Additional survey content included demographics and questions related to screening attitudes and other possible influences on screening discussions and recommendations (Supplementary material). 


\section{Provider screening attitudes}

Separately from the scenarios, five items assessed providers' prostate cancer- and CRC-screening attitudes. These items were modified from similar items developed to measure patients' screening attitudes for each of the screening types. ${ }^{38}$ The items had a 5-point response scale ranging from strongly agree (5) to strongly disagree (1). After reverse-coding two items, we averaged the five items within each screening type (prostate and CRC) and by age (70- and 90-year-olds only), resulting in four attitude scores per provider (range 5-25): for prostate cancer screening for hypothetical 70 - and 90-yearold patients, and for CRC screening for hypothetical 70 and 90 -year-old patients. A high score indicated positive attitudes toward screening and a low score a lack of positive attitudes toward screening. The survey included separate measures of screening attitudes for hypothetical patients aged 70 and 90 years, because providers' attitudes toward screening may differ by patient age. Scores demonstrated adequate reliability (Cronbach's $\alpha=0.69$ ).

\section{Other potentially influential factors}

We also included four single-item questions to address the potential influence of time spent with the patient, worry about lawsuits, the value of performance measures and reminders, and current screening guidelines. The first three items had a common stem, and read "To what degree would the following factors influence your recommendation for (prostate/colon cancer screening) for a 70-year-old male patient? 1) short time to spend with the patient; 2) worry I could be sued; and 3) clinical reminders or performance measures", based on the Choosing Wisely campaign and Guerra et al's work. ${ }^{44,45}$ Each item had a 4-point response scale that ranged from no influence (1) to strong influence (4). The item assessing the perceived influence of current screening guidelines was, "How much influence does the USPSTF have on your screening recommendations?" This investigator-created item had a 5-point response scale ranging from not at all influential (1) to extremely influential (5).

\section{Informed consent and patient details}

When the surveys were distributed, we informed providers that participation was voluntary. Receipt of the completed survey was taken as consent to participate. Completion was encouraged, but not mandatory. Completion of the survey was neither a prerequisite for employment, nor were providers who did not complete the survey censured in any way. We confirmed all participants' identifiers had been removed or disguised so that the patient/person(s) described are not identifiable and cannot be identified through the details of the manuscript.

\section{Statistical analysis}

We summarized study-sample characteristics using descriptive analyses. For questions on hypothetical scenarios, we tabulated separately the percentage of providers who would discuss and recommend prostate cancer and CRC screening under each age and request for screening condition. We then examined the association of screening test (prostate cancer or CRC), patient age $(50,70$, or 90 years), and patient request (yes/no) with whether providers said they would discuss and whether they would recommend cancer screening, using simple generalized linear mixed models with logit-link functions that included each predictor as a covariate and the effects of clustering within providers as a random effect. Analyses did not adjust for the random effects of clustering of providers within clinics. Additionally, we examined interactions among test, age, and patient request and the outcomes of discussion and recommendations. Analyses did not include scenarios in which the patient was 50 years, because in some scenarios $100 \%$ of providers would discuss or recommend screening, leaving no variance around these data points for analysis. We continued to remove nonsignificant interaction terms from the model in a reverse stepwise fashion until our final models retained only the significant variables and interaction terms at $P<0.1$.

We used descriptive statistics to examine screening attitudes and other factors that may influence provider recommendations. We also compared mean screening attitudes between the hypothetical scenarios with 70-year-old and 90 -year-old patients using paired samples $t$-tests. We also compared mean results on the other perceived influential factors using paired $t$-tests. Finally, we conducted additional analyses better to understand providers' reported recommendations of the "lowest-value" screening by creating two new dichotomous outcome measures of expected lowest-value prostate cancer and CRC screening. Any recommendation for prostate cancer screening in a 90 -year-old patient was considered of lowest value for prostate cancer screening, and any recommendation for CRC screening in a 90-year-old patient was considered of lowest value for CRC screening.

Finally, we conducted exploratory analyses using logistic regressions of the lowest-value screening services (prostate or CRC) as outcomes and corresponding cancer-screening attitudes and other factors as predictors. These analyses were considered exploratory, because we were not powered to detect differences in these groups. We conducted all analyses 
using SAS 9.3 (SAS Institute, Cary, NC, USA) with critical $\alpha=0.05$ using two-tailed analyses. We took into account clustering within providers whenever an analytic variable involved two or more responses from a clinician.

\section{Results}

We received completed surveys from 126 of the 158 primarycare providers ( $80 \%$ response rate). Most respondents were female (62\%), white (77\%), physicians (77\%), and had a strictly clinical role $(76 \%)$ (Table 1$)$. Providers' mean age was 45 (range 29-69) years, with a mean of 15 (range 1-40) years in practice.

\section{Cancer-screening discussions and recommendations}

More providers indicated they would discuss cancer screening than recommend cancer screening in response to the scenarios about hypothetical patients. Overall, 75\% (95\% CI $73 \%-78 \%$ ) would discuss cancer screening and 51\% (95\% CI $48 \%-54 \%$ ) recommend cancer screening (Figure 2). However, the frequency of providers saying they would discuss and recommend screening differed by screening type, age, and patient request.

Table I Participant characteristics $(n=126)^{a}$

\begin{tabular}{ll}
\hline Characteristics & $\mathbf{n}(\%) /$ mean (SD) \\
\hline Age (years) & $45(0.9)$ \\
Female & $77(62)$ \\
Race & $12(10)$ \\
African-American & $14(11)$ \\
Asian-American & $95(77)$ \\
Caucasian & $3(2)$ \\
Others & $2(2)$ \\
Refused/missing & $4(3)$ \\
Hispanic & \\
Professional training & $95(77)$ \\
Doctor of Medicine & $3(2)$ \\
Doctor of Osteopathic Medicine & $10(8)$ \\
Nurse practitioner & $14(11)$ \\
Physician's assistant & $2(2)$ \\
Others & $2(2)$ \\
Missing & \\
Primary clinical role & $93(76)$ \\
Clinician & $23(19)$ \\
Clinician-educator & $3(2)$ \\
Clinician-researcher & $4(3)$ \\
Others & $3(2)$ \\
Missing & $15(0.8)$ \\
Time in medical practice (years) &
\end{tabular}

Notes: ane provider who answered all other survey questions did not answer demographic questions.

\section{Differences in cancer-screening discussions by type of screening, patient age, and patient request}

Providers were more likely to report that they would discuss screening when it was for CRC than prostate cancer $(P<0.001)$, for younger than older patients $(P<0.001)$, and for patients who requested it than those who did not $(P<0.001)$ (Figure 2). After exclusion of responses about patients aged 50 years, two interactions qualified these findings: providers reported hypothetical cancer-screening discussions more often for the 70-year-old patient than the 90 -year-old patient for CRC, as opposed to prostate cancer $(P<0.001$ for the interaction of age and screening test), and for the 70 -year-old patient than the 90 -yearold patient for those who requested the test compared to those who did not $(P=0.014$ for the interaction of age and patient request).

\section{Differences in cancer-screening recommendations by type of screen, patient age, and patient request}

Providers would recommend screening more frequently for CRC than for prostate cancer $(P<0.001)$, more frequently for younger patients than for older patients $(P<0.001)$, and more frequently for those who requested it than for those who did not $(P<0.001)$ (Figure 2). Providers reported they would recommend screening more often for the 70-year-old patient than the 90-year-old patient for CRC compared to prostate cancer $(P<0.001$ for the interaction of age and screening test). Therefore, while $95 \%$ of providers recommended CRC screening for a patient aged 70 years (regardless of request for screening) and $4 \%$ recommended it at age 90 years, only $39 \%$ of providers recommended prostate screening at age 70 years and $3 \%$ for a patient aged 90 years. The interaction of age and patient request also approached statistical significance $(P=0.08)$, ie, providers were more likely to recommend screening for the 70-year-old patient than the 90 -year-old patient if the patient requested screening compared to those who did not.

\section{Recommendations for low-value screening}

Providers infrequently said they would recommend the lowest-value screening for a hypothetical 90 -year-old patient. In the face of patient requests, only $7 \%$ of providers would recommend prostate cancer screening for a hypothetical 


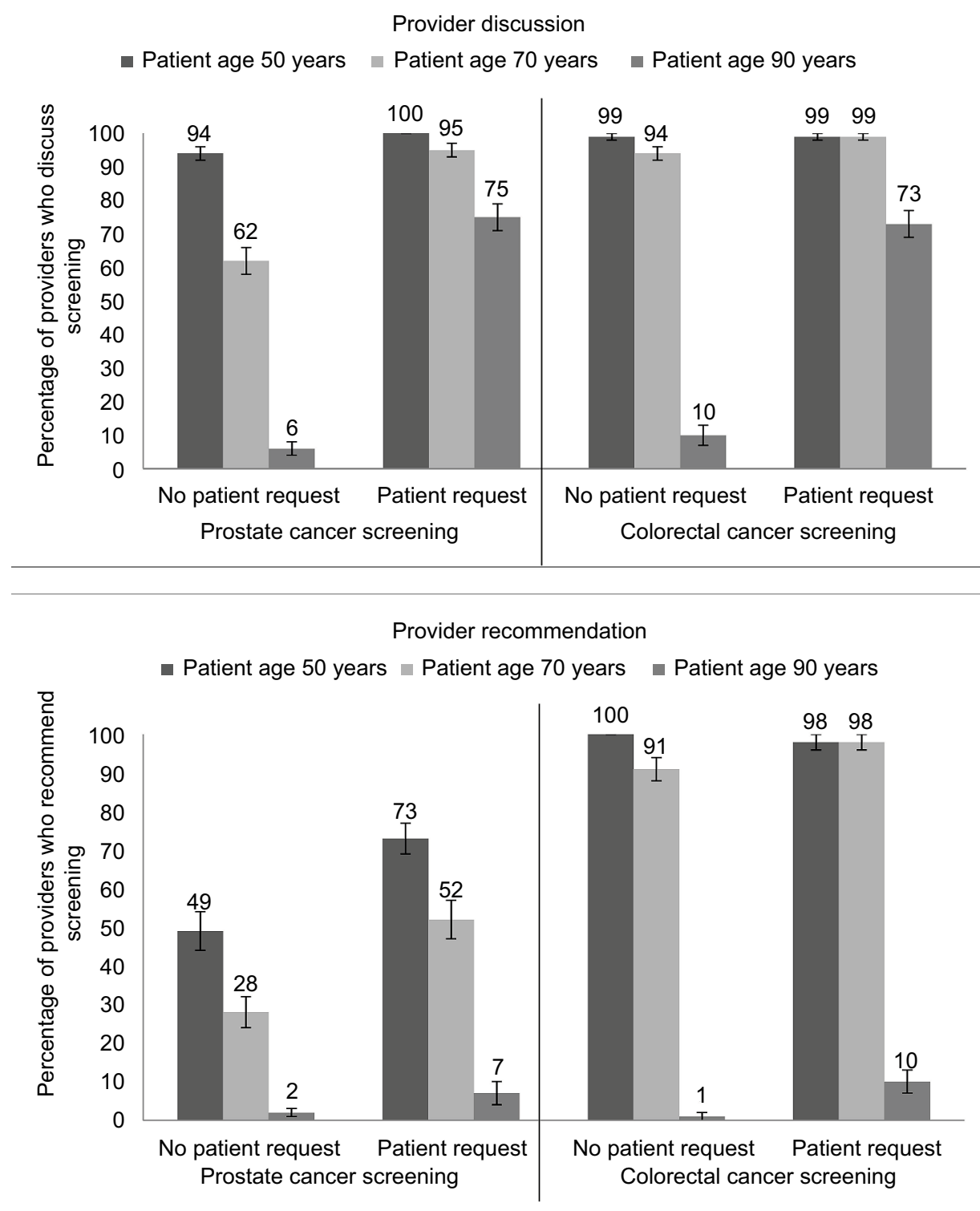

Figure 2 When providers would discuss and recommend screening $(n=126){ }^{a}$

Notes: ${ }^{2}$ For prostate cancer-screening discussion scenario, $n=122$; for colorectal cancer-screening discussion scenario, $n=124$; for prostate cancer-screening recommendation scenario, $n=1 / 8$; for colorectal cancer-screening recommendation scenario, $n=123$.

90-year-old, whereas $10 \%$ would recommend CRC screening for a hypothetical 90-year-old patient. Expanding our definition of low-value prostate cancer screening to all men aged $\geq 50$ years in accordance with the 2012 USPSTF recommendations, we found that $73 \%$ of providers reported they would recommend prostate cancer screening for a hypothetical 50-year-old patient who requested it. In accordance with the recently updated USPSTF recommendations, low-value prostate cancer screening was still high: $52 \%$ of providers reported they would recommend prostate cancer screening for a hypothetical 70-year-old patient who requested it.

\section{Providers' cancer-screening attitudes and other factors}

The five screening attitudes can be found in Table 2. Cancerscreening attitudes for both prostate cancer and CRC screening were less positive for 90 -year-old patients than for younger patients (both $P<0.001$ for overall scale). Furthermore, in a 70-year-old male, providers reported that clinical reminders/performance measures influenced their recommendations more than short patient visits or lawsuit worries (both $P<0.001$ ) for both prostate cancer and CRC screening. The average perceived influence of clinical reminders/ performance measures for prostate cancer screening was 
Table 2 Screening attitudes and perceived influence on recommendations by screening type and patient age $(n=126)^{a}$

\begin{tabular}{|c|c|c|c|c|}
\hline & \multicolumn{2}{|c|}{ Prostate cancer screening } & \multicolumn{2}{|c|}{ Colorectal cancer screening } \\
\hline & $\begin{array}{l}\text { Age } 70 \text { years, } \\
\text { mean (SD) }\end{array}$ & $\begin{array}{l}\text { Age } 90 \text { years, } \\
\text { mean (SD) }\end{array}$ & $\begin{array}{l}\text { Age } 70 \text { years, } \\
\text { mean (SD) }\end{array}$ & $\begin{array}{l}\text { Age } 90 \text { years, } \\
\text { mean (SD) }\end{array}$ \\
\hline \multicolumn{5}{|l|}{ Cancer-screening attitudes } \\
\hline $\begin{array}{l}\text { I would feel like I had done something wrong if I did not recommend that } \\
\text { my patients have regular screening for (prostate/colorectal) cancer. }\end{array}$ & $2.4(1.4)$ & I.4 (0.8) & $4.1(1.0)$ & $\mathrm{I} .5(0.8)$ \\
\hline $\begin{array}{l}\text { I do not feel any special responsibility to recommend screening for } \\
\text { (prostate/colorectal) cancer. }\end{array}$ & $2.8(1.3)$ & $1.9(1.3)$ & $4.4(1.0)$ & $\mathrm{I} .8(\mathrm{I} .2)$ \\
\hline $\begin{array}{l}\text { When it comes to recommending (prostate/colorectal) cancer screening, } \\
\text { it is better to be safe than sorry. }\end{array}$ & $2.6(1.2)$ & $1.5(0.9)$ & $4.0(1.0)$ & $\mathrm{I} .8(\mathrm{I} . \mathrm{I})$ \\
\hline Screening for (prostate/colorectal) cancer is just looking for trouble. ${ }^{b}$ & $2.9(1.1)$ & I.8 (I.I) & $4.5(0.8)$ & $2.3(1.4)$ \\
\hline $\begin{array}{l}\text { I would regret not recommending (prostate/colorectal) cancer screening } \\
\text { to a patient later diagnosed with (prostate/colorectal) cancer. }\end{array}$ & $3.5(1.2)$ & $2.1(1.2)$ & $4.4(1.0)$ & $2.4(1.2)$ \\
\hline Summary scale & $2.8(1.2)$ & $\mathrm{I} .7(\mathrm{I} . \mathrm{I})$ & $4.3(0.9)$ & $1.9(1.1)$ \\
\hline \multicolumn{5}{|l|}{$\begin{array}{l}\text { Perceived influence of other factors on screening } \\
\text { recommendations }\end{array}$} \\
\hline Clinical reminders/performance measures & $2.6(0.1)$ & NA & $2.9(0.1)$ & NA \\
\hline Short patient visits & $2.1(0.1)$ & NA & $2.0(0.1)$ & NA \\
\hline Worry about lawsuits & $2.3(0.1)$ & NA & $2.1(0.1)$ & NA \\
\hline
\end{tabular}

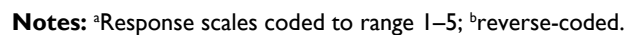

Abbreviation: NA, not assessed.

2.6, which was higher than the average perceived influence of short patient visits and worries about lawsuits: 2.1 and 2.3, respectively. For CRC screening, the mean influence of clinical reminders/performance measures was 2.9 , which was higher than the averages for short patient visits and worries about lawsuits: 2.0 and 2.1, respectively. Providers perceived guidelines as influential, such that $90 \%$ of providers reported that USPSTF guidelines were very or extremely influential in their screening recommendations.

\section{Associations among recommendations for lowest-value screening and cancer- screening attitudes and other factors}

Providers' attitudes toward screening 90-year-old patients were associated with their recommendations for lowest-value screening. For every 1-point increase in prostate cancerscreening attitudes for a 90-year-old patient, the likelihood of a provider reporting a recommendation for screening increased by $30 \%$ (relative risk ratio $1.3,95 \%$ CI 1.1-1.5). Similarly, for every 1-point increase in CRC-screening attitudes for a 90-year-old patient, the likelihood of a provider reporting a recommendation for screening increased by $30 \%$ (relative risk ratio 1.3, 95\% CI 1.2-1.5). Exploratory analysis of other potentially influential factors found no associations among providers' perceptions of the influence of USPSTF guidelines, short patient visits, worries about lawsuits, or clinical reminders/performance measures reported recommendations for screening a hypothetical 90-year-old.

\section{Discussion}

In our study of 126 US primary-care providers, providers appropriately reported they would discuss cancer screening more often than they would recommend it. They would also discuss and recommend screening for CRC more often than for prostate cancer and for younger patients more often than for older patients, both of which are generally appropriate. However, approximately $10 \%$ stated they would recommend prostate cancer and CRC screening for a 90 -year-old, despite research showing that the balance of benefits and harms favors harm, eg, the lowest-value screening. Further, while a majority would discuss prostate cancer screening in a 70-year-old or 90-year-old in the absence of a patient request; more concerning, some would recommend prostate cancer screening when faced with a patient request. Therefore, while most providers' practice patterns aligned with high-value care, some did not.

Echoing other studies, our work shows that both patient age and patient request appear to influence discussions and recommendations. ${ }^{31-33,46}$ Moreover, we found that these factors modified each other's influence, thus providing a more nuanced look at the interaction between age and request. Like other research, ${ }^{47}$ we also found that increasing patient age decreased providers' recommendations for both lowvalue screening tests. Our choice of age cutoffs allowed for comparison between screening tests, but did not reflect most prostate cancer- and CRC-screening guideline age cutoffs. Our choice of age cutoffs compared to various guidelines 
may explain some of the findings for CRC screening, given the overwhelming majority of medical providers would recommend screening for a hypothetical 50- and 70-yearold patient, but not a hypothetical 90-year-old. However, guidelines are unlikely to explain our results for prostate cancer screening. However, while other studies examined such factors singly, ${ }^{48}$ our findings suggest that patient requests may lead to recommendations even in the face of advanced age, a practice that would be in direct opposition to current guideline recommendations. ${ }^{49}$ Additionally, our study shows that even in the absence of requests, providers still sometimes report they would engage in clinically inappropriate discussions and recommendations.

Consistent with other work, we found that several screening factors affected provider recommendations for screening. ${ }^{50-52}$ Our work also extends the existing literature by examining the association of recommendations with provider attitudes, guideline endorsement, and environmental factors (performance measures, visit times, and lawsuit worries). Not surprisingly, we found that providers with more positive screening attitudes toward prostate cancer or CRC screening were more likely to report they would recommend screening. ${ }^{23,53}$ In contrast to other work, ${ }^{54,55}$ however, we did not find a relationship between reporting that guidelines are influential and the recommendations for low-value screening in 90-yearolds. Additionally, while performance measures and incentives were rated as more influential than short visit times and worry about lawsuits, this was not associated with rates of low-value screening recommendations. These findings may be due to the small number of providers who would recommend screening in these subgroups, resulting in inadequate power to detect a difference if present. Given performance measures released from the Agency for Healthcare Research and Quality on "the percentage of men 70 years and older who were screened unnecessarily for prostate cancer using PSA-based screening", ${ }^{56}$ the influence of performance measures on actual prostate screening will require close follow-up and study.

Numerous approaches to align discussions and recommendations with high-value care are possible. ${ }^{57}$ For example, because we know that patient requests influence providers' discussions and recommendations, we may be able to develop techniques for providers to address patient requests instead of offering services that are likely to harm patients. ${ }^{58}$ Based on our findings, these approaches may need to differ for prostate cancer and CRC screening. For instance, given our findings that providers' perceive guidelines as influential, but not associated with lowest-value screening recommendations, efforts may need to focus on increasing providers' agreement with and their self-efficacy to implement guidelines. They may also need to include resources and environmental redesign to support guideline implementation, deal with conflicting guidelines, ${ }^{59}$ or increase provider cultural awareness of the need for change ${ }^{48}$ (such as the Choosing Wisely campaign, which includes numerous resources for these efforts). ${ }^{60}$ Further, if performance measures were to influence actual provider recommendations, then health care-insurance groups, other payers, or health care systems may need to incentivize high-value care and deincentivize low-value care through such measures. ${ }^{61,62}$ Systems might also consider providing other forms of system-level supports (eg, electronic healthrecord support prompts or stop alerts). ${ }^{48,63}$ Clinical decision support may also include individualized information about life expectancy and the appropriateness of screening for an individual patient. ${ }^{64}$ Patients often distrust guidelines and their medical providers when the providers recommended against screening. ${ }^{65,66}$ If patients raise the issue of screening for services with net harm, the shared decision-making workgroup suggested a discussion and a recommendation against the services (particularly if recommendations have changed) $;{ }^{3}$ however, providers may find this suggestion difficult to follow and may need help in addressing their worries

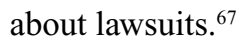

In interpreting our study, readers should place it in its proper context in the evidence hierarchy. This study was designed to help us to understand the relationships between three key factors that potentially affect provider discussions and recommendations for screening (eg, test type, age, and patient request) and generate some hypotheses about the relationships among other variables (eg, attitudes, measures and incentives, short visit times, and worry about lawsuits) and discussion and recommendations. While the design is adequate for these tasks, there are several issues of which the reader should be aware.

First, we used a novel survey design using two screeningscenario decisions (discuss/recommend), each with three age permutations and a request/no request status, rather than 12 separate scenarios. This design likely affected how the questions were perceived and answered, because our design did not account for all possible ordering effects and anchoring bias. ${ }^{68}$ Second, we did not ask providers whether they would recommend against screening either, but only whether they would recommend for it, which could have potentially altered the responses. Third, we offered no definition in our survey of what constitutes a discussion or a recommendation, and our scenarios included information on prior screening history that may have biased responses. Given that most providers 
currently do not meet proposed standards for an informed discussion and recommendation, ${ }^{69,70}$ we believed that provision of a definition might influence providers away from reporting a discussion or recommendation. Fourth, the scenarios were only hypothetical, and focused on only two cancer-screening services. Real-life discussions and recommendations by providers in real clinical encounters may differ from hypothetical scenarios, as might provider behavior for other types of screening, such as breast cancer screening. Fifth, providers may have given socially desirable answers, such that actual rates of discussions and recommendations for low-value screening could differ from what we found here. Sixth, some of our measures have not been formally validated. Seventh, the study population was limited to central North Carolina, which may not reflect the attitudes or behavior of primarycare providers in other geographic areas. We also tasked clinic representatives with recruiting participants, which may have altered which participants chose to participate, though our project manager did email all of the providers as well. While they were all within one health care system in North Carolina, the clinics included a mix of clinics in the urban, small-town, and rural settings, and we recruited $80 \%$ of all eligible practice providers. In addition, none of the participants were physicians in training nor did we look at subgroups of primary-care providers. Lastly, both screening guidelines and definitions of value have changed since this study was conducted, and the definitions and guidelines may change providers' responses.

\section{Conclusion}

While most providers' reported practice patterns aligned with high-value care, some providers would discuss prostate cancer screening in the absence of patient requests, and some would recommend low-value care, particularly when faced with patient requests. In this study of two common cancerscreening services, we found that few providers would discuss or recommend the lowest-value screening. However, patient requests appeared to encourage low-value recommendations, particularly for prostate cancer screening (even at advanced patient ages).

Future work is needed to reproduce our findings in larger, more diverse populations and to explore interventions for addressing the influence of patient requests and physicians' screening attitudes on provider behaviors in regard to discussions and recommendations for low-value care. To the extent that the medical community seeks to optimize the net value of care by increasing delivery of high-value services and decreasing delivery of low-value services, there is clearly more work to be done.

\section{Acknowledgments}

The authors would like to thank Carol Golin and Emily Elstad for their assistance in writing this manuscript. This work was supported by the Agency for Healthcare Research and Quality grant for a Research Center for Excellence in Clinical Preventive Services P01 HS021133-01 (center principal investigator $\mathrm{RPH}$ and project principal investigator MV) and the Agency for Healthcare Research and Quality Mentored Career Development Program in Comparative Effectiveness Development grant K12 HS19468-01. The funding sources had no role in the study design, collection, analysis, or interpretation of data, writing the report, or the decision to submit the report for publication. The content of this paper is solely the responsibility of the authors and does not necessarily represent the official views of the Agency for Healthcare Research and Quality.

\section{Disclosure}

The authors report no conflicts of interest in this work.

\section{References}

1. Harris RP, Wilt TJ, Qaseem A. A value framework for cancer screening: advice for high-value care from the American College of Physicians. Ann Intern Med. 2015;162(10):712-717.

2. Bhatia RS, Levinson W, Shortt S, et al. Measuring the effect of choosing wisely: an integrated framework to assess campaign impact on low-value care. BMJ Qual Saf. 2015;24(8):523-531.

3. Sheridan SL, Harris RP, Woolf SH. Shared decision making about screening and chemoprevention. a suggested approach from the U.S. Preventive Services Task Force. Am J Prev Med. 2004;26(1):56-66.

4. Cassel CK, Guest JA. Choosing wisely: helping physicians and patients make smart decisions about their care. JAMA. 2012;307(17):1801-1802.

5. Schwartz AL, Landon BE, Elshaug AG, Chernew ME, McWilliams JM. Measuring low-value care in Medicare. JAMA Intern Med. 2014;174(7):1067-1076.

6. Schwartz LM, Woloshin S, Fowler FJ Jr, Welch HG. Enthusiasm for cancer screening in the United States. JAMA. 2004;291(1):71-78.

7. Prasad V, Vandross A, Toomey C, et al. A decade of reversal: an analysis of 146 contradicted medical practices. Mayo Clin Proc. 2013;88(8):790-798.

8. Elshaug AG, Watt AM, Mundy L, Willis CD. Over 150 potentially low-value health care practices: an Australian study. Med J Aust. 2012;197(10):556-560.

9. Wilt TJ, Harris RP, Qaseem A. Screening for cancer: advice for highvalue care from the American College of Physicians. Ann Intern Med. 2015;162(10):718-725.

10. Schreuders EH, Ruco A, Rabeneck L, et al. Colorectal cancer screening: a global overview of existing programmes. Gut. 2015;64(10): 1637-1649.

11. Navarro M, Nicolas A, Ferrandez A, Lanas A. Colorectal cancer population screening programs worldwide in 2016: an update. World $J$ Gastroenterol. 2017;23(20):3632-3642.

12. Lin JS, Piper MA, Perdue LA, et al. Screening for colorectal cancer: updated evidence report and systematic review for the US Preventive Services Task Force. JAMA. 2016;315(23):2576-2594.

13. Force USPST. Prostate cancer screening draft recommendations. 2017. Available from: https://screeningforprostatecancer.org. Accessed March 8, 2018. 
14. Gomella LG, Liu XS, Trabulsi EJ, et al. Screening for prostate cancer: the current evidence and guidelines controversy. Can J Urol. 2011;18(5):5875-5883.

15. Moyer VA. Screening for prostate cancer: U.S. Preventive Services Task Force recommendation statement. Ann Intern Med. 2012;157(2): 120-134.

16. Tang VL, Shi Y, Fung K, et al. Clinician factors associated with prostatespecific antigen screening in older veterans with limited life expectancy. JAMA Intern Med. 2016;176(5):654-661.

17. Kistler CE, Kirby KA, Lee D, Casadei MA, Walter LC. Long-term outcomes following positive fecal occult blood test results in older adults: benefits and burdens. Arch Intern Med. 2011;171(15):1344-1351.

18. Schonberg MA, Leveille SG, Marcantonio ER. Preventive health care among older women: missed opportunities and poor targeting. Am J Med. 2008;121(11):974-981.

19. Royce TJ, Hendrix LH, Stokes WA, Allen IM, Chen RC. Cancer screening rates in individuals with different life expectancies. JAMA Intern Med. 2014;174(10):1558-1565.

20. Bellizzi KM, Breslau ES, Burness A, Waldron W. Prevalence of cancer screening in older, racially diverse adults: still screening after all these years. Arch Intern Med. 2011;171(22):2031-2037.

21. Yabroff KR, Klabunde CN, Yuan G, et al. Are physicians' recommendations for colorectal cancer screening guideline-consistent? J Gen Intern Med. 2011;26(2):177-184.

22. Nodora JN, Martz WD, Ashbeck EL, et al. Primary care physician compliance with colorectal cancer screening guidelines. Cancer Causes Control. 2011;22(9):1277-1287.

23. Tasian GE, Cooperberg MR, Cowan JE, et al. Prostate specific antigen screening for prostate cancer: knowledge of, attitudes towards, and utilization among primary care physicians. Urol Oncol. 2012;30(2):155-160.

24. Petitti DB, Teutsch SM, Barton MB, Sawaya GF, Ockene JK, DeWitt T. Update on the methods of the U.S. Preventive Services Task Force: insufficient evidence. Ann Intern Med. 2009;150(3):199-205.

25. Lee SJ, Boscardin WJ, Stijacic-Cenzer I, Conell-Price J, O’Brien S, Walter LC. Time lag to benefit after screening for breast and colorectal cancer: meta-analysis of survival data from the United States, Sweden, United Kingdom, and Denmark. BMJ. 2013;346:e8441.

26. Walter LC, Lindquist $\mathrm{K}$, Nugent $\mathrm{S}$, et al. Impact of age and comorbidity on colorectal cancer screening among older veterans. Ann Intern Med. 2009;150(7):465-473.

27. Walter LC, Bertenthal D, Lindquist K, Konety BR. PSA screening among elderly men with limited life expectancies. JAMA. 2006;296(19):2336-2342.

28. Walter LC, Fung KZ, Kirby KA, et al. 5-Year downstream outcomes following prostate-specific antigen (PSA) screening in older men. JAMA Intern Med. 2013;173(10):866-873.

29. Walter LC, Covinsky KE. Cancer screening in elderly patients: a framework for individualized decision making. JAMA. 2001;285(21): 2750-2756.

30. Fraenkel L, Fried TR. Individualized medical decision making: necessary, achievable, but not yet attainable. Arch Intern Med. 2010;170(6):566-569.

31. Pollack CE, Noronha G, Green GE, Bhavsar NA, Carter HB. Primary care providers' response to the US Preventive Services Task Force draft recommendations on screening for prostate cancer. Arch Intern Med. 2012;172(8):668-670.

32. Keitz SA, Stechuchak KM, Grambow SC, Koropchak CM, Tulsky JA. Behind closed doors: management of patient expectations in primary care practices. Arch Intern Med. 2007;167(5):445-452.

33. Lewis CL, Griffith J, Pignone MP, Golin C. Physicians' decisions about continuing or stopping colon cancer screening in the elderly: a qualitative study. J Gen Intern Med. 2009;24(7):816-821.

34. Gogineni K, Shuman KL, Chinn D, Gabler NB, Emanuel EJ. Patient demands and requests for cancer tests and treatments. JAMA Oncol. 2015;1(1):33-39.
35. Pollack CE, Platz EA, Bhavsar NA, et al. Primary care providers' perspectives on discontinuing prostate cancer screening. Cancer. 2012;118(22):5518-5524.

36. Pearson SD, Goldman L, Orav EJ, et al. Triage decisions for emergency department patients with chest pain: do physicians' risk attitudes make the difference? J Gen Intern Med. 1995;10(10):557-564.

37. Sirovich BE, Woloshin S, Schwartz LM. Too little? Too much? Primary care physicians' views on US health care: a brief report. Arch Intern Med. 2011;171(17):1582-1585

38. Sheridan SL, Sutkowi-Hemstreet A, Barclay C, et al. A comparative effectiveness trial of alternate formats for presenting benefits and harms information for low-value screening services: a randomized clinical trial. JAMA Intern Med. 2016;176(1):31-41.

39. Hoddinott SN, Bass MJ. The Dillman total design survey method. Can Fam Physician. 1986;32:2366-2368.

40. Dresselhaus TR, Peabody JW, Lee M, Wang MM, Luck J. Measuring compliance with preventive care guidelines: standardized patients, clinical vignettes, and the medical record. J Gen Intern Med. 2000;15(11):782-788

41. Peabody JW, Luck J, Glassman P, Dresselhaus TR, Lee M. Comparison of vignettes, standardized patients, and chart abstraction: a prospective validation study of 3 methods for measuring quality. JAMA. 2000;283(13):1715-1722.

42. Dillman DA. Mail and Internet Surveys: The Tailored Design Method. 2nd ed. Hoboken (NJ): Wiley; 2007.

43. Thorpe C, Ryan B, McLean SL, et al. How to obtain excellent response rates when surveying physicians. Fam Pract. 2009;26(1):65-68.

44. Guerra CE, Gimotty PA, Shea JA, Pagán JA, Schwartz JS, Armstrong $\mathrm{K}$. Effect of guidelines on primary care physician use of PSA screening: results from the Community Tracking Study physician survey. Med Decis Making. 2008;28(5):681-689.

45. PerryUndem Research/Communication. Unnecessary tests and procedures in the health care system. 2014. Available from: http://www. choosingwisely.org/wp-content/uploads/2015/04/Final-ChoosingWisely-Survey-Report.pdf. Accessed March 8, 2018.

46. Haggerty J, Tudiver F, Brown JB, Herbert C, Ciampi A, Guibert R. Patients' anxiety and expectations: how they influence family physicians' decisions to order cancer screening tests. Can Fam Physician. 2005;51:1658-1659.

47. Cohn JA, Wang CE, Lakeman JC, et al. Primary care physician PSA screening practices before and after the final U.S. Preventive Services Task Force recommendation. Urol Oncol. 2014;32(1):41.e23-e30.

48. Cabana MD, Rand CS, Powe NR, et al. Why don't physicians follow clinical practice guidelines? A framework for improvement. JAMA. 1999;282(15):1458-1465.

49. Sabbatini AK, Tilburt JC, Campbell EG, Sheeler RD, Egginton JS, Goold SD. Controlling health costs: physician responses to patient expectations for medical care. J Gen Intern Med. 2014;29(9):1234-1241.

50. Heflin MT, Pollak KI, Kuchibhatla MN, Branch LG, Oddone EZ. The impact of health status on physicians' intentions to offer cancer screening to older women. J Gerontol A Biol Sci Med Sci. 2006;61(8):844-850.

51. Cooper GS, Fortinsky RH, Hapke R, Landefeld CS. Primary care physician recommendations for colorectal cancer screening: patient and practitioner factors. Arch Intern Med. 1997;157(17):1946-1950.

52. Haggstrom DA, Klabunde CN, Smith JL, Yuan G. Variation in primary care physicians' colorectal cancer screening recommendations by patient age and comorbidity. J Gen Intern Med. 2013;28(1):18-24.

53. Hoffman RM, Papenfuss MR, Buller DB, Moon TE. Attitudes and practices of primary care physicians for prostate cancer screening. $\mathrm{Am}$ J Prev Med. 1996;12(4):277-281.

54. Tudiver F, Brown JB, Medved W, et al. Making decisions about cancer screening when the guidelines are unclear or conflicting. J Fam Pract. 2001;50(8):682-687.

55. Leach CR, Klabunde CN, Alfano CM, Smith JL, Rowland JH. Physician over-recommendation of mammography for terminally ill women. Cancer. 2012;118(1):27-37. 
56. Agency for Healthcare Research and Quality. Non-recommended prostate-specific antigen (PSA)-based screening in older men: percentage of men 70 years and older who were screened unnecessarily for prostate cancer using PSA-based screening. 2016. Available from: https://www.qualitymeasures.ahrq.gov/summaries/summary/50442. Accessed March 9, 2018.

57. Damschroder LJ, Aron DC, Keith RE, Kirsh SR, Alexander JA, Lowery JC. Fostering implementation of health services research findings into practice: a consolidated framework for advancing implementation science. Implement Sci. 2009;4:50.

58. Paterniti DA, Fancher TL, Cipri CS, Timmermans S, Heritage J, Kravitz RL. Getting to "no": strategies primary care physicians use to deny patient requests. Arch Intern Med. 2010;170(4):381-388.

59. Carpenter DM, Geryk LL, Chen AT, Nagler RH, Dieckmann NF, Han PK. Conflicting health information: a critical research need. Health Expect. 2016;19(6):1173-1182.

60. Levinson W, Kallewaard M, Bhatia RS, Wolfson D, Shortt S, Kerr EA. 'Choosing Wisely': a growing international campaign. BMJ Qual Saf. 2015;24(2):167-174.

61. Mamede S, Splinter TA, van Gog T, Rikers RM, Schmidt HG. Exploring the role of salient distracting clinical features in the emergence of diagnostic errors and the mechanisms through which reflection counteracts mistakes. BMJ Qual Saf. 2012;21(4):295-300.

62. Doran T, Maurer KA, Ryan AM. Impact of provider incentives on quality and value of health care. Annu Rev Public Health. 2017;38:449-465.
63. Yabroff KR, Zapka J, Klabunde CN, et al. Systems strategies to support cancer screening in U.S. primary care practice. Cancer Epidemiol Biomarkers Prev. 2011;20(12):2471-2479.

64. Stacey D, Légaré F, Col NF, et al. Decision aids for people facing health treatment or screening decisions. Cochrane Database Syst Rev. 2014;4:CD001431.

65. Lantz PM, Evans WD, Mead H, Alvarez C, Stewart L. Knowledge of and attitudes toward evidence-based guidelines for and against clinical preventive services: results from a national survey. Milbank $Q$. 2016;94(1):51-76.

66. Carman KL, Maurer M, Yegian JM, et al. Evidence that consumers are skeptical about evidence-based health care. Health Aff (Millwood). 2010;29(7):1400-1406.

67. Barry MJ, Wescott PH, Reifler EJ, Chang Y, Moulton BW. Reactions of potential jurors to a hypothetical malpractice suit alleging failure to perform a prostate-specific antigen test. J Law Med Ethics. 2008;36(2):396-402.

68. Hsee CK, Zhang J. General evaluability theory. Perspect Psychol Sci. 2010;5(4):343-355.

69. Wackerbarth SB, Tarasenko YN, Joyce JM, Haist SA. Physician colorectal cancer screening recommendations: an examination based on informed decision making. Patient Educ Couns. 2007;66(1):43-50.

70. McQueen A, Bartholomew LK, Greisinger AJ, et al. Behind closed doors: physician-patient discussions about colorectal cancer screening. J Gen Intern Med. 2009;24(11):1228-1235.
International Journal of General Medicine

\section{Publish your work in this journal}

The International Journal of General Medicine is an international, peer-reviewed open-access journal that focuses on general and internal medicine, pathogenesis, epidemiology, diagnosis, monitoring and treatment protocols. The journal is characterized by the rapid reporting of reviews, original research and clinical studies across all disease areas.

\section{Dovepress}

The manuscript management system is completely online and includes a very quick and fair peer-review system, which is all easy to use. Visit http://www.dovepress.com/testimonials.php to read real quotes from published authors. 